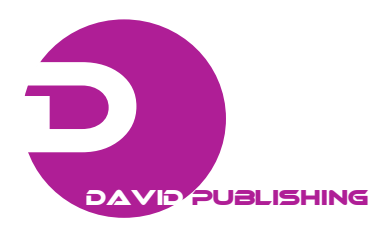

\title{
Potentials of Diverse Safe and Functional Vegetable Production through Organic Method in the Small Scale Farming of Bangladesh
}

\author{
M Nazim Uddin \\ Olericulture Division, Horticulture Research Centre, Bangladesh Agricultural Research Institute (BARI), Gazipur 1701, Dhaka, \\ Bangladesh \\ Corresponding author's e-mail:nazim.68@gmail.com
}

\begin{abstract}
Safe food is the human right and the demand of the safe food is old. Due to the complexity of food and the natural presence of potential hazards, the assurance of food safety is not a simple matter. Almost any single definition of safe food will be overly simplistic, because safe food is a complex, multifaceted concept. According to the World Health Organization/Food and Agriculture Organization (FAO), food is considered safe if there is reasonable certainty that no harm will result from its consumption under anticipated conditions of use (CAC/GL45-2003). The FAO further explains that the goal of any safety assessment is to provide assurance, in the light of the best available scientific knowledge, that the food does not cause harm when prepared, used and/or eaten according to its intended use. The absolute safety of a food or an ingredient can never be guaranteed. However, with appropriate precautions during production and distribution, the risk from any food can be kept to an absolute minimum that is generally acceptable to consumers. Vegetable consumption is increasing in Bangladesh due to growing awareness of health. But the production of vegetables is not enough for requirement. Moreover, the method of production mostly depends on petroleum based chemical fertilizers and pesticides. Nowadays to increase the vegetables production, indiscriminate use of such ingredient makes the produced unsafe and hazardous, which is carcinogenic to the public health. Less vegetable toxic substances does not comply the safe but its functional properties also need to be considered. Production method like organic, is the only way to ensure the quality, functional properties and safety of vegetables. Moreover, diverse productions of vegetables from same piece of small land may increase the diversity of nutrient and functional food. This paper will focus on how to grow diverse safe and functional food from the same land in a growing season in Bangladesh condition.
\end{abstract}

Key words: Functional vegetable, organic farming, diversification, production, Bangladesh. 